
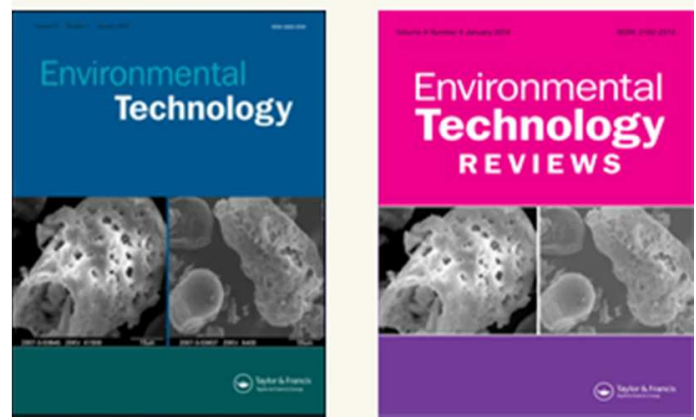

\title{
Microbial community analysis in biotrickling filters treating isopropanol air emissions
}

\begin{tabular}{|r|l|}
\hline Journal: & Environmental Technology \\
\hline Manuscript ID: & OA-2012-1331.R1 \\
\hline Manuscript Type: & Original Article \\
\hline Date Submitted by the Author: & 22-Mar-2013 \\
\hline Complete List of Authors: & $\begin{array}{l}\text { Pérez, M. Carmen; University of Valencia, } \\
\text { Alvarez, F. Javier; University of Valencia, } \\
\text { San Valero, Pau; University of Valencia, } \\
\text { Marzal, Paula; University of Valencia, } \\
\text { Gabaldón, Carmen; University of Valencia, Chemical Engineering Dept. }\end{array}$ \\
\hline Keywords: & $\begin{array}{l}\text { biotrickling filters, denaturing gradient gel electrophoresis, fluorescence in } \\
\text { situ hybridisation, microbial community, volatile organic compounds }\end{array}$ \\
\hline
\end{tabular}

SCHOLARONE ${ }^{m}$

Manuscripts 


\title{
Microbial community analysis in biotrickling filters treating isopropanol air emissions
}

\author{
M. Carmen Pérez, F. Javier Álvarez-Hornos, Pau San-Valero, Paula Marzal, \\ Carmen Gabaldón* \\ Research Group GI2AM, Department of Chemical Engineering, Universitat de València, Av. \\ de la Universidad s/n, 46100, Burjassot, Spain \\ *Corresponding author. Carmen Gabaldón, Department of Chemical Engineering, Universitat \\ de València, Av. de la Universidad s/n, 46100, Burjassot, Spain. Tel.: +34963543437; fax: \\ +34963544898. E-mail: carmen.gabaldon@uv.es (Carmen Gabaldón). URLs: \\ http://www.uv.es/giam; http://www.nextairbiotreat.eu/
}




\title{
Microbial community analysis in biotrickling filters treating isopropanol air emissions
}

\begin{abstract}
The evolution of the microbial community was analysed over one year in two biotrickling filters operating under intermittent feeding conditions and treating isopropanol emissions, a pollutant typically found in the flexography sector. Each reactor was packed with one media: plastic cross-flow-structured material or polypropylene rings. The communities were monitored by fluorescence in situ hybridisation (FISH) and denaturing gradient gel electrophoresis (DGGE) analysis of the $16 \mathrm{~S}$ rRNA region. After inoculation with activated sludge, the biotrickling filters were operated using inlet loads (ILs) from 20 to $65 \mathrm{~g} \mathrm{C} \mathrm{m}^{-3} \mathrm{~h}^{-1}$ and empty bed residence times (EBRTs) from 14 to $160 \mathrm{~s}$. Removal efficiencies higher than $80 \%$ were obtained with ILs up to $35 \mathrm{~g} \mathrm{C} \mathrm{m}^{-3} \mathrm{~h}^{-1}$ working at EBRTs as low as $24 \mathrm{~s}$. There was an increase in the total percentage of the target domains of up to around $80 \%$ at the end of the experiment. Specifically, Gammaproteobacteria domain group, which includes the well-known volatile organic compund (VOC)-degrading species such as Pseudomonas putida, showed a noticeable rise in the two biotrickling filters of $26 \%$ and $27 \%$, respectively. DGGE pattern band analysis revealed a stable band of Pseudomonas putida in all the samples monitored, even in the lower diversity communities. In addition, at similar operational conditions, the biotrickling filter with a greater relative abundance of Pseudomonas sp. (19.2\% vs. 8\%) showed higher removal efficiency (90\% vs. 79\%). Results indicate the importance of undertaking a further in-depth study of the involved species in the biofiltration process and their specific function.
\end{abstract}

Keywords: biotrickling filters; denaturing gradient gel electrophoresis; fluorescence in situ hybridisation; microbial community; volatile organic compounds. 


\section{Introduction}

Flexography is part of the printing sector and its industry grew by $4.5 \%$ from 2009 to 2010 , comprising around 150,000 companies in Europe [1]. The main organic solvents used in flexography are ethanol and isopropyl alcohol, since they are used in the formulation of solvent inks, dilution and cleaning processes [2]. Stricter requirements for the control of volatile organic compounds (VOCs) from the use of solvents have been published by a new European Directive on industrial emissions (Council Directive 2010/75/EC), in which VOC emission limits have been established between values of 50 and $150 \mathrm{mg} \mathrm{C} \mathrm{Nm}^{-3}$ depending on the industrial activity. Thus, the flexographic industry requires treatment technologies to comply with the directive regulating VOC emission.

There are several techniques for treating VOC emissions, such as condensation, adsorption, absorption, thermal destruction and biotechnologies. Biotechnologies, including biofilters, biotrickling filters and bioscrubbers, are a potential alternative to conventional techniques for removing VOCs from emission streams with high flow rates and relatively low VOC concentrations. Moreover, these have proven to be both cost-effective and environmentally friendly [3]. Furthermore, biological treatment has been included as an endof-pipe technique for waste gas abatement in installations for the surface treatment of substances using organic solvents [4].

Biotrickling filters (BTFs) use a specified inert packing material and involve a liquid phase, which trickles through the bed providing nutrients. The biofilm is developed on the packing surface, the microbial community being essential for the successful performance of the process. The effectiveness of the BTF process has been studied from the laboratory to the industrial scale treating aromatic and oxygenated compounds [5-13]. However, there is little 
data in the literature on compounds related to the flexographic sector. For example, Chang and Lu studied the removal of isopropanol (IPA) using a trickled-bed air biofilter packed with coal and empty bed residence times (EBRTs) from 20 to $90 \mathrm{~s}$ [14]. Removal efficiencies

(REs) between 90 and 99\% were achieved for inlet loads (ILs) of between 45 and $88 \mathrm{~g} \mathrm{C} \mathrm{m}^{-3}$ $\mathrm{h}^{-1}$. Krailas and Pham reported an isopropanol elimination capacity (EC) of $276 \mathrm{~g} \mathrm{~m}^{-3} \mathrm{~h}^{-1}$ for an IL of $342 \mathrm{~g} \mathrm{~m}^{-3} \mathrm{~h}^{-1}$ using a downward flow biofilter [15]. Popov et al. evaluated a pilotscale biotrickling filter at a flexographic printing facility employing an EBRT of $14 \mathrm{~s}$ [16]. Highly variable VOC emissions containing a mixture of alcohols and esters, with an average inlet concentration of $1.56 \mathrm{~g} \mathrm{~m}^{-3}$, were treated with an average RE of $89 \%$.

As reported above, main efforts have been made to improve the feasibility and robustness of the bioprocess; however, there are few studies focused on the characterisation of the bacterial population in BTFs. For this purpose, molecular biological techniques are useful for analysing microbial community structures during the removal of contaminants in the biological processes. Some of the applied techniques are polymerase chain reaction singlestrand conformation polymorphism (PCR-SSCP), denaturing gradient gel electrophoresis (DGGE) and fluorescence in situ hybridisation (FISH). PCR consists of amplifying nucleotide fragments and SSCP detects sequence variations (single-point mutations and other small-scale changes) through electrophoretic mobility differences. DGGE is based on the electrophoretic separation of PCR products with the same length, but with different sequences, on a linear denaturing gradient polyacrylamide gel [17]. FISH detects nucleic acid sequences by probes with fluorescent dyes that hybridises specifically to its complementary target sequence within the cell [18]. These techniques have been applied in the field of biofiltration $[19,20]$. For example, Khammar et al. studied the spatial structure of microbial communities in a biofilter treating a complex mixture of 11 VOCs using PCR-SSCP. The authors observed a 
spatialisation of the biodegradation functions in the biofilter related to the stratification of microbial density and diversity along the filter bed [21]. In another study, Friedrich et al. applied FISH to determine the bacterial community in a full-scale industrial biofilter [22]. Results indicated that members of the Betaproteobacteria, Actinobacteria, Alphaproteobacteria, Cytophaga-Flavobacteria, Firmicutes and Gammaproteobacteria were the most abundant groups, although a non-homogeneous distribution along the biofilter was observed, since the lower $50 \mathrm{~cm}$ of the biofilter bed was the most active in removing pollutants. The DGGE technique was applied to assess the impact of changing VOC emission composition on the bacterial community structure in a trickle-bed air biofilter during 192 days [23]. The results showed that the structure of the microbial community in the biofilter was different after each change in the inlet composition.

The purpose of this work was to characterise the microbial communities present in two biotrickling filters, each one with a different packing material (a plastic cross-flowstructured material or polypropylene rings) for treating isopropanol (IPA) emissions. The following specific objectives were developed: (1) application of FISH and DGGE to analyse any variation in the microbial communities following changes in the operating parameters of the BTFs; (2) comparison between the microbial communities in the two BTFs.

\section{Material and methods}

\subsection{BTF set-up and operating conditions}

The experimental system consisted of two identical laboratory-scale BTFs operating in parallel, named BTF1 and BTF2. The schematic of the experimental set-up is shown in Figure 1. Both BTFs were built by a methacrylate column with a total length of $126 \mathrm{~cm}$ and an 
internal diameter of $14.4 \mathrm{~cm}$. BTF1 was filled with a plastic cross-flow-structured packing material (Odourpack, Pure Air Solutions, the Netherlands) with a surface area of $410 \mathrm{~m}^{2} \mathrm{~m}^{-3}$, and BTF2 with a random packing material (Refill-Tech, Italy) consisting of polypropylene rings with a nominal diameter of $5 / 8$ " and a surface area of $348 \mathrm{~m}^{2} \mathrm{~m}^{-3}$. The set-up was completed with a 10 -L recirculation tank and the recirculation solution was intermittently fed into the bioreactor ( 15 min every $1.5 \mathrm{~h}$ ) in a counter-current mode with respect to the air flow. The liquid velocity was set to $10 \mathrm{~m} \mathrm{~h}^{-1}$. A nutrient solution $\left(21.65 \mathrm{~g} \mathrm{KNO}_{3} \mathrm{~L}^{-1}, 4.6 \mathrm{~g}\right.$ $\mathrm{Na}_{3} \mathrm{PO}_{4} \cdot 12 \mathrm{H}_{2} \mathrm{O} \mathrm{L}{ }^{-1}$, trace elements $\left(\mu \mathrm{g} \mathrm{L}^{-1}\right): 12000 \mathrm{Ca}, 1500 \mathrm{Fe}, 2650 \mathrm{Mg}, 605 \mathrm{Zn}, 60 \mathrm{Co}, 60$ Mo, $55 \mathrm{Ni}, 50 \mathrm{Cu}, 45 \mathrm{~B}, 40 \mathrm{Mn}, 8 \mathrm{I}, 3 \mathrm{Se} \& 1 \mathrm{Cr}$; and vitamins $\left(\mu \mathrm{g} \mathrm{L}^{-1}\right): 20$ beta-Carotene, 70 B1, 70 B2, 95 B6, 10 B9, 0.1 B12, 3 C, 0.3 D, 500 E, 2 Biotin \& 900 Niacin) was supplied into the recirculation tank using a peristaltic pump to maintain a supplied mass ratio of carbon to nitrogen of 35 . The inoculum for both BTFs was an activated sludge obtained from a wastewater treatment plant located in Valencia (Spain). An inoculum volume of $0.5 \mathrm{~L}$ (TSS concentration of $3500 \mathrm{mg} \mathrm{L}^{-1}$ ) was added to the recirculation tank and continuously flowed through the bed for $24 \mathrm{~h}$.

The influence of IL and EBRT on the removal of isopropanol and microbial communities were analysed in three phases (A, B and C). Each phase was designed with a constant inlet concentration. In the phases A, B and C, it was adjusted to 1000,500 and 250 $\mathrm{mg} \mathrm{C} \mathrm{Nm}{ }^{-3}$, respectively. For each phase, several IL step increases were carried out together with variations in the EBRTs of between 14 and $160 \mathrm{~s}$ (gas velocities between 258 and $23 \mathrm{~m}$ $\mathrm{h}^{-1}$ ). Table 1 summarises the experimental plan and the biomass sampling events. The experiments were planned to simulate typical industrial emissions, hence an intermittent loading pattern was applied (16 h of feeding isopropanol per day, 5 days per week). During nights and weekends without isopropanol supply, the air flow rate was kept constant and the 
water trickling was stopped. The first three biomass samples (day 60 at phase A-II, 100 at phase B-II and 130 at phase C-I) corresponded to experiments with an IL of $35 \mathrm{~g} \mathrm{C} \mathrm{m}^{-3} \mathrm{~h}^{-1}$ and a gradual reduction of the EBRT from 90 to $24 \mathrm{~s}$.

In the last phase (D), the effects on the system re-start-up after a long period without isopropanol feeding was evaluated to check the robustness of the process and the impact on the microbial community. Macroscopic changes such as RE recovery and microscopic changes such as the microbial ecology structure were evaluated. During the period from day 164 to day 217 (referred to here as the starvation period), the supply of isopropanol was stopped, the air flow rate was adjusted to achieve an EBRT of $60 \mathrm{~s}$ and the water trickling pattern was reduced to $15 \mathrm{~min}$ per day. On day 217 , VOC feeding was restored using the same intermittent pattern applied before ( $16 \mathrm{~h}$ of feeding isopropanol per day, 5 days per week) and the trickling of water for 15 min every $4 \mathrm{~h}$ was set. In phase D-I, an IL of $35 \mathrm{~g} \mathrm{C}$ $\mathrm{m}^{-3} \mathrm{~h}^{-1}$ and an EBRT of $60 \mathrm{~s}$ were established. A few days after isopropanol feeding was restored (on day 217), a new biomass sample was obtained on day 227 (at phase D-I). Finally, the IL was twice increased at phase D-II and two biomass samples (days 245 and 276) were collected. Results of the removal of both BTFs during phases A, B and C have been previously published by the authors on San-Valero et al. [24]. A summary of these results are presented here in order to show the complete performance of both BTFs during whole experimental period (from phase A to D). The performance is used to correlate him with the microbial communities analysed from biomass samples taken throughout entire experimental period.

\subsection{Fluorescence in situ hybridization (FISH)}

The FISH technique was carried out, adapting the procedure described by Amann et al. [25]. 
The procedure included the following steps: sampling, fixation, hybridisation with the respective probes for detecting the respective target sequences, image acquisition and analysis. The probes targeting general bacterial groups used in this work were:

Alphaproteobacteria, Betaproteobacteria and Gammaproteobacteria related to the Proteobacteria domain, Firmicutes (low G+C Gram-positive bacteria) and Actinobacteria (high $\mathrm{G}+\mathrm{C}$ Gram-positive bacteria). These groups have been previously identified as the main ones involved in VOC removal [26,27]. Pseudomonas sp., Pseudomonas putida, Bacillus and Mycobacterium were the targeted species monitored since previous studies have indicated that these species play an important role in VOC degradation [28-32].

\subsubsection{Sampling and fixation}

Biomass samples from the bioreactors were taken from three sampling ports located at different heights of the packed bed of the reactor: 20,62 and $105 \mathrm{~cm}$. They were mixed at a 1:1:1 ratio (wt) and disaggregated with an Ultra-Turrax (IKA ${ }^{\circledR}$ T18 basic, Germany), resulting in one sample for each BTF. The samples were fixed using the procedure described by Amann at al. [25]. According to the procedure, each sample was fixed with two methods: (1) to analyse Gram-negative cells where the sample was fixed with paraformaldehyde solution (4\% in PBS). The sample was incubated at $4^{\circ} \mathrm{C}$ for $2 \mathrm{~h}$. Then, the biomass was pelleted by centrifugation for $3 \mathrm{~min}$ at $7000 \mathrm{rpm}$, washed with PBS, pelleted again and finally, re-suspended in PBS solution; (2) to analyse Gram-positive cells, the sample was centrifuged for $3 \mathrm{~min}$ at $7000 \mathrm{rpm}$ and re-suspended with ethanol solution (96\%).

\subsubsection{Hybridisation}

In this study, a Cy5-labelled EUBmix as the general probe and Cy3-labelled specific probes

(Thermo Fisher Scientific, Germany) were used. EUBmix consists of a 1:1:1 (vol) mixture of 
the probes EUB338, EUB338II and EUB338III. Fluorochromes Cy5 and Cy3 with different wavelengths for excitation and emission allow simultaneous microscopic observations. The oligonucleotide probes used in this study and the percentage of formamide used for each probe are summarised in Table 2 [33]. Hybridisation was performed at $46^{\circ} \mathrm{C}$ for $2 \mathrm{~h}$. After this step, the slides were rinsed for $18 \mathrm{~min}$ at $48^{\circ} \mathrm{C}$, dried and mounted. For mounting, an anti-fading product (VECTASHIELD ${ }^{\circledR}$, ATOM S.A, Spain) was used to avoid the loss of fluorescence.

\subsubsection{Image acquisition and analysis}

Slides were examined using a Leica TCS SP confocal laser scanning microscope (CLSM, Leica Microsystems, Germany). The microscope is equipped with two He-Ne lasers with light emissions at 543 and $633 \mathrm{~nm}$. Each image captured was formed with two pictures, one corresponding to EUBmix and the other to the specific probe. Five images were acquired for the negative control (without probes) and 30 for the stained samples (with specific and general probes). Specific probes were quantified as the proportion of EUBmix-labelled bacteria using image analysis based on the methodology developed by Jubany et al. [34]. This method was implemented in the Matlab ${ }^{\circledR}$ software. First, the thresholds for general and specific probes were calculated as the minimum intensity value satisfying the condition: the proportion of pixels with intensity lower or equal to the threshold value in the negative control images is greater or equal to a value of $99.9 \%$. These thresholds were used to exclude the autofluorescense of the sample in the quantification procedure. The quantification of images for the stained samples was carried out as the sum of the pixels with intensity higher than the threshold intensity for the general and specific probes. Finally, the ratio of the sum of the pixels for the specific probe to that for the general probe was estimated. 


\subsection{DNA extraction and PCR amplification}

DNA was extracted using a JETQUICK tissue DNA Spin kit (Genycell biotech, Spain) from the biomass samples taken on days 60, 100, 227 and 276 (phases A-II, B-II, D-I and D-II, respectively). DNA was stored at $-20^{\circ} \mathrm{C}$ until analysis. The extracted DNA was used as the target DNA in PCR to amplify the 16S rRNA coding regions, using two universal primers for the bacterial domain, primer F357GC:

5'CGCCCGCCGCGCGCGGCGGGCGGGGCGGGGGCACGGGGGGCCTACGGGAGGC AGCAG3' and primer R518: 5'ATTACCGCGGCTGCTGG3'. A GC clamp was added to the forward primers to facilitate the DGGE. PCR was performed in 50 - $\mu 1$ reaction volume using a mixture containing 0.1 units/ $\mu \mathrm{l}$ of Taq DNA polymerase, $3.2 \mathrm{mM}$ dNTPs, $3 \mathrm{mM} \mathrm{MgCl} 232$ $\mathrm{mM}\left(\mathrm{NH}_{4}\right)_{2} \mathrm{SO}_{4}, 134 \mathrm{mM}$ Tris $\mathrm{HCl}$ and $0.2 \mu \mathrm{M}$ of each primer (EuroClone, Italy).

PCR was executed in a thermal cycler (LongGene Scientific Instruments, Hangzhou) using the temperature cycling conditions described by Muyzer and Ramsing [17]. It consisted of 20 cycles of: $94^{\circ} \mathrm{C}$ for $1 \mathrm{~min}, 65^{\circ} \mathrm{C}$ for $1 \mathrm{~min}$, a gradual decrease in the temperature using $0.5^{\circ} \mathrm{C}$ increments until $55^{\circ} \mathrm{C}$, followed by $72{ }^{\circ} \mathrm{C}$ for $3 \mathrm{~min}$. The PCR reactions followed with 10 cycles of: $94{ }^{\circ} \mathrm{C}$ for $1 \mathrm{~min}, 55^{\circ} \mathrm{C}$ for $1 \mathrm{~min}$ and $72{ }^{\circ} \mathrm{C}$ for $3 \mathrm{~min}$. A final extension at $72{ }^{\circ} \mathrm{C}$ for 7 min was undertaken as the final step.

\subsection{DGGE analysis}

Five $\mu 1$ of the PCR product was separated on a $2 \%$ agarose gel at $100 \mathrm{~V}$ for 30 min to verify the correct amplification before DGGE. For DGGE analysis, the PCR product generated from each sample was separated on an $8 \%$ acrylamide gel using a linear denaturant gradient increasing from $35 \%$ to $60 \%$ using the KuroGel Verti 2020 DGGE System (VWR 
international Eurolab S.L.). DGGE was performed using $20 \mu \mathrm{l}$ of PCR product in 1xTAE buffer at $60{ }^{\circ} \mathrm{C}$ with a sequence of $50 \mathrm{~V}$ for $5 \mathrm{~min}, 150 \mathrm{~V}$ for $120 \mathrm{~min}$ and $200 \mathrm{~V}$ for $60 \mathrm{~min}$.

\section{Results and discussion}

\subsection{BTF performance}

The performances of the two biotrickling filters treating IPA emissions, BTF1 and BTF2, are presented in Figure 2a and 2b, respectively. The performance was evaluated in terms of inlet load (IL), elimination capacity (EC) and removal efficiency (RE). Table 3 summarises the performance of both BTFs on the days the biomass samples were taken. As can be observed in Figure 2, approximately two weeks after inoculation, the systems were able to achieve stable REs of around $80 \%$ (phase A-I, $160 \mathrm{~s}$ of EBRT and IL of $20 \mathrm{~g} \mathrm{C} \mathrm{m}^{-3} \mathrm{~h}^{-1}$ ). A decrease in the EBRT to 90 and $50 \mathrm{~s}$ at phases A-II and A-III, respectively, caused a decrease in RE for both BTFs with values varying from 60 to $85 \%$. In phase B, the inlet concentration was set at $500 \mathrm{mg} \mathrm{C} \mathrm{Nm}^{-3}$ and the EBRT was adjusted to 90,50 and $25 \mathrm{~s}$ for phases B-I, B-II and B-III, respectively. REs greater than $90 \%$ were obtained in phases B-I and B-II, whereas in phase BIII, the RE dropped to values of $60-70 \%$. In phase $C$, the inlet concentration was set at $250 \mathrm{mg}$ $\mathrm{C} \mathrm{Nm}^{-3}$ and the EBRT was adjusted to 24 and $14 \mathrm{~s}$ for phases C-I and C-II, respectively. In these phases with the most demanding operational conditions, the performances of the two systems were slightly different. For example, in phase C-I using an IL of $35 \mathrm{~g} \mathrm{C} \mathrm{m}^{-3} \mathrm{~h}^{-1}$ and an EBRT of $24 \mathrm{~s}$, RE values of around $80 \%$ and $88 \%$ were observed for BTF1 and BTF2, respectively. Prior to the starvation period, the minimum EBRT (14s) was applied at phase CII and the RE decreased to values of $49 \%$ and $60 \%$ for BTF 1 and BTF2, respectively. 
The starvation period took place from day 164 to day 217 to evaluate the re-start-up of the process after restoring VOC feeding. Macroscopic changes such as RE recovery and microscopic changes such as the microbial ecology structure were evaluated. On day 217 , VOC feeding was restored using the same intermittent pattern applied before ( $16 \mathrm{~h}$ of feeding isopropanol per day, 5 days per week) and the trickling of water for 15 min every $4 \mathrm{~h}$ was set. In phase D-I, an IL of $35 \mathrm{~g} \mathrm{C} \mathrm{m}^{-3} \mathrm{~h}^{-1}$ and an EBRT of $60 \mathrm{~s}$ were established. Ten days after restoring VOC feeding, both BTFs achieved REs as high as $90 \%$, similar to those observed during phase B-II, demonstrating that the BTFs could handle long periods without VOC feeding. In the last phase (D-II) where the IL was twice increased to $65 \mathrm{~g} \mathrm{C} \mathrm{m}^{-3} \mathrm{~h}^{-1}$, average RE values of $72 \%$ and $80 \%$ were reached in BTF1 and BTF2, respectively.

\subsection{Monitoring of bacterial community by FISH}

The monitoring of the bacterial community in the biofilm samples of both BTFs was carried out by FISH over the entire experimental period in which different operational conditions were tested (Table 1).

Figure 3 shows the evolution of the relative abundance of the general bacterial groups for the two BTFs, BTF1 (Figure 3a) and BTF2 (Figure 3b), on days 60, 100, 130, 227, 245 and 276. The results were expressed as the percentage of EUBmix-stained cells (hereafter defined as total bacteria). The total percentages of the target domains calculated as the sum of each general bacterial group are summarised in Table 4 for BTF1 and BTF2

Total percentage values ranged from 29.7 to $79.2 \%$ and from 69.4 to $88.1 \%$ for BTF 1 and BTF2, respectively. It is worth noting that the higher value of the total identified bacterial groups was observed at the last phase in both BTFs $(79.2 \%$ and $88.1 \%$ for BTF1 and BTF2, respectively). This could be explained by the specialisation of the microbial community to 
groups and/or species more suitable for degrading the pollutant (IPA) during the year of experimentation. Other authors have indicated that the development of highly diverse communities could be enhanced in environments with high resource availability [35]. For example, Álvarez-Hornos et al. studied microbial populations in pilot-scale biotrickling installed in a plastic coating factory to control complex emissions with highly variable VOC composition [36]. The authors reported high bacterial diversity and heterogeneity, with total percentages of the same bacterial groups as those in this study varying between $23 \%$ and $56 \%$ relative to the EUBmix counts, with no predominant groups.

Regarding the evolution of the general bacterial groups, their composition changed over time and was influenced by the operational conditions in both BTFs, although there were some patterns that could be considered. As seen in Figure 3, the Gram-negative bacteria identified (Alphaproteobacteria, Betaproteobacteria and Gammaproteobacteria) were more abundant than the Gram-positive bacteria identified (Firmicutes and Actinobacteria). A deep examination of the results indicated different trends for each group. For example, members of Alphaproteobacteria and Betaproteobacteria were the most fluctuating groups, with values ranging between $4 \%$ and $27 \%$ and $7 \%$ and $22 \%$, respectively. Firmicutes and Actinobacteria groups presented a less oscillating behaviour, especially in BTF2 with an average value of $12 \%$ for both groups. The percentage of the Gammaproteobacteria group increased throughout the experimental period in both BTFs, being the most abundant group at the end of experiment with values of $26 \%$ and $27 \%$ for BTF 1 and BTF2, respectively. This rise could be explained by the ability of Gammaproteobacteria species to degrade VOCs [30-32,37,38], enabling them to develop better in environments rich in VOC. It should be noted that in BTF2, where greater RE and greater quantity of biomass attached to the packing (visual inspections during the tested period) were obtained in comparison with BTF1, the 
Gammaproteobacteria group was the most abundant in almost all samples, with values higher than $20 \%$. As an example, Figure 4 shows a relatively high quantity of Gammaproteobacteria in BTF2 on day 276.

Regarding changes in certain bacterial species, Figure 5 represents their timedependent changes in BTF1 (Figure 5a) and BTF2 (Figure 5b) on days 60, 100, 130, 227, 245 and 276. The total percentage of identified species calculated as the sum of Pseudomonas sp., Bacillus and Mycobacterium presented a pattern similar to that observed with the general bacterial groups. For example, from day 100 onwards (phase B-II), the total percentage of identified species in BTF2 was higher than that in BTF1, achieving an average value of $34.3 \%$ in comparison with an $18.4 \%$, respectively.

A detailed analysis of the species in both BTFs showed a slight variation for Bacillus with values ranging between $1.5 \%$ and $10.5 \%$, whereas Mycobacterium presented a greater fluctuation with values between 0.7 and $16 \%$, especially during the days after the starvation period when it displayed the highest values $(16.0 \%$ and $14 \%$ for BTF1 and BTF2, respectively). This could be explained by the fact that Mycobacterium is better protected against stressful periods without substrates and nutrients, due to the characteristics of its cell membrane. Regarding Pseudomonas sp., a common species in environments rich in VOCs [29-31], several issues can be highlighted. As seen in Figure 5, the observed percentage of Pseudomonas sp. was always higher than that of Pseudomonas putida. The samples from BTF2 presented Pseudomonas sp. as the predominant species, with values ranging between $8 \%$ and $29 \%$. In addition, these percentages were higher than those observed in BTF1, where Pseudomonas $s p$. showed a stable behaviour with an average value of $4.3 \%$. These results agree with the bacterial evolution previously presented in Figure 3, where the abundance of Gammaproteobacteria in BTF2 was higher than that in BTF1. In fact, the most abundant group in BTF2 was Gammaproteobacteria and the most abundant species Pseudomonas sp. The differences between the ecological communities observed in the two BTFs could be attributed to different internal environment characteristics of the biofilm of each system. The use of two packing materials with different structure and surface area could elicit changes 
such as transfer to and diffusion into the biofilm of VOC, oxygen and nutrients or different degrees of biomass detachment, wetted area and distribution of irrigation. The oxygen mass transfer coefficients $\left(\mathrm{k}_{\mathrm{L}} \mathrm{a}\right)$ of the packings have been estimated by San-Valero et al. [24], with a similar value for both materials of approximately $50 \mathrm{~h}^{-1}$ at a liquid velocity of $10 \mathrm{~m} \mathrm{~h}^{-1}$ and values of 125 and $175 \mathrm{~h}^{-1}$ for random and structured packing, respectively, when a liquid velocity of $30 \mathrm{~m} \mathrm{~h}^{-1}$ was used. All these changes at the microscopic scale affect the microbial community of the biofilm, which finally result in different behaviours at the macroscopic scale. In fact, BTF2, with a higher abundance of species belonging to Gammaproteobacteria such as Pseudomonas sp., produced greater REs than BTF1 (Table 3). For example, at phases C-I and D-II, RE values of 81.4 and 79\% were observed for BTF1, and 88.7 and $90 \%$ for BTF2. It is worth noting that at the liquid velocity applied in the study, $10 \mathrm{~m} \mathrm{~h}^{-1}$, the packing materials of both BTFs present a similar value of the $\mathrm{k}_{\mathrm{L}} \mathrm{a}\left(50 \mathrm{~h}^{-1}\right)$. Therefore, the greater RE reached in BTF2 could be due to the higher population of these species, since the random packing (BTF2) does not present better mass-transfer properties. Changes in the performance of the system with changes in the microbial community show the importance of further studying the involved species during the removal process.

\subsection{Monitoring of bacterial community by DGGE}

In parallel to FISH analyses, DGGE was performed to compare the 16SrDNA fragments of bacteria in the samples collected from both BTFs on different operational days. DGGE band patterns for samples taken on days 60, 100, 227 and 276 are presented in Figure 6. The samples were also compared to a control sample of an enriched batch culture of Pseudomonas putida. Analysis of DGGE patterns revealed changes in the structure of the bacterial community during the experimental period. After 276 days of operation, there was a decrease in the number of bands in both BTFs, indicating lower diversity in the microbial community at the end of the experiment. The fact that this was also observed in the FISH analyses could be explained by the specialisation of specific groups and/or species that are more suitable for degrading the pollutant. It should be noted that despite the difference in the bacterial community structure as revealed by the DGGE patterns, some bands appeared in all the 
samples analysed, indicating that several species could survive these conditions because of their ability to survive in environments rich in VOCs and/or participate in their degradation. As shown in Figure 6, one of these stable bands matched the culture enriched with Pseudomonas putida, corroborating the presence of this species in environments with VOCs.

\section{Conclusions}

Two biotrickling filters treating intermittent emissions contaminated with isopropanol were monitored over almost one year and the microbial communities were analysed by FISH and DGGE. Both BTFs were inoculated with the same inoculum, the same pollutant was removed by the two systems, and the same operational and maintenance conditions were applied, the only difference between the two being the type of packing material used. Under these conditions, the random packing material showed a slightly higher capacity for removal. At the end of the experiment, the relative abundance of the Gammaproteobacteria group was observed to increase in both BTFs, with values of around $26 \%$. This rise could be associated with the increase in the species belonging to this group such as Pseudomonas sp., predominant species in BTF2 with values between $8 \%$ and $29 \%$, while in BTF1, it exhibited a stable trend with an average value of $4.3 \%$. Moreover, DGGE analysis confirmed the presence of Pseudomonas putida in all the samples monitored, even in the less diverse communities observed at the end of the experiment. The differences in the microbial community of both BTFs could be linked to the difference in the performances of the systems. For example, BTF2 displayed a removal efficiency of $90 \%$ compared to the $79 \%$ shown by BTF1 at phase D-II. Furthermore, in BTF2, the percentage of the common species present in VOC-rich environments such as Pseudomonas sp. was twice as much as that observed in BTF1 (19.2\% and $8 \%$, respectively). Results show the importance of further studying the involved species during the removal process, e.g. future studies include the application of new 
molecular biological tools as next-generation sequencing methods.

\section{Acknowledgements}

The research leading to these results has received funding from the People Programme (Marie Curie Actions) of the European Union's Seventh Framework Programme FP7/2007-2013/ under REA grant agreement $n^{\circ} 284949$. Financial support from the Ministerio de Ciencia e Innovación (Project CTM2010-15031/TECNO) and the Generalitat Valenciana (ACOMP/2012/209) are also acknowledged. We are also grateful for the FPU grant from the Ministerio de Educación, Cultura y Deporte (Spain).

\section{References}

[1] Eurostat, http://epp.eurostat.ec.europa.eu/portal/page/portal/eurostat/home/, 2012.

[2] European Commission. Guidance on VOC Substitution and Reduction for Activities Covered by the VOC Solvents Emissions Directive (Directive 1999/13/EC). Contract ENV/C.4/FRA/2007/001; 2009.

[3] G. Wu, J. Chabot, J. Caron and M. Heitz, Biological elimination of volatile organic compounds from waste gases in a biofilter, Water Air Soil Pollut. 101 (1998), pp. 69-78.

[4] European Commission, IPPC reference document on best available techniques in surface treatment using organic solvents, 2007.

[5] J. Paca, E. Klapkova, M. Halecky, K. Jones and T.S. Webster, Interactions of hydrophobic and hydrophilic solvent component degradation in an air-phase biotrickling filter reactor, Environ. Prog. 25 (2006), pp. 365-372.

[6] V. Martínez-Soria, C. Gabaldón, J.M. Penya-Roja, J. Palau, F.J. Álvarez-Hornos, F. Sempere and C. Soriano, Performance of a pilot-scale biotrickling filter in controlling the volatile organic compound emissions in a furniture manufacturing facility, J. Air Waste Manage. Assoc. 59 (2009), pp. 998-1006. 
[7] F. Sempere, C. Gabaldón, V. Martínez-Soria, P. Marzal, J.M. Penya-roja and F.J. ÁlvarezHornos, Performance evaluation of a biotrickling filter treating a mixture of oxygenated VOCs during intermittent loading, Chemosphere 73 (2008), pp. 1533-1539.

[8] H.H.J. Cox, T. Sexton, Z.M. Shareefdeen and M.A. Deshusses, Thermophilic biotrickling filtration of ethanol vapors, Environ. Sci. Technol. 35 (2001), pp. 2612-2619.

[9] D. Kim, Z. Cai and G. Sorial, Behavior of trickle-bed air biofilter for toluene removal: Effect of non-use periods, Environ. Prog. 24 (2005), pp. 155-161.

[10] K. Morotti, A.A. Ramirez, J.P. Jones and M. Heitz, Analysis and comparison of biotreatment of air polluted with ethanol using biofiltration and biotrickling filtration, Environ. Technol. 32 (2011), pp. 1967-1973.

[11] M.A. Garzón-Zúñiga, P. Lessard and G. Buelna, Determination of the hydraulic residence time in a trickling biofilter filled with organic matter, Environ. Technol. 24 (2003), pp. 605-614.

[12] G. Baquet, J.C. Joret, F.Rogalla and M.M. Bourbigot, Biofilm start-up and control in aerated biofilter, Environ. Technol. 12 (1991), pp. 747-756.

[13] H.H.J. Cox and M.A. Deshusses, Innovative experimental setup for the parallel operation of multiple bench scale biotrickling filters for waste air treatment, Environ. Technol. 21 (2000), pp. 427-435.

[14] K. Chang and C. Lu, Biofiltration of isopropyl alcohol by a trickle-bed air biofilter, Biodegradation 14 (2003), pp. 9-18.

[15] S. Krailas and Q. Pham, Macrokinetic determination and water movement in a downward flow biofilter for methanol removal, Biochem. Eng. J. 10 (2002), pp. 103-113.

[16] V. Popov, A. Bezborodov, M. Cavanagh and P. Cross, Evaluation of industrial biotrickling filter at the flexographic printing facility, Environ. Prog. 23 (2004), pp. 39-44.

[17] G. Muyzer and N. Ramsing, Molecular methods to study the organization of microbial communities, Water Sci. Technol. 32 (1995), pp. 1-9.

[18] A. Moter and U. Gobel, Fluorescence in situ hybridization (FISH) for direct visualization of microorganisms, J. Microbiol. Methods 41 (2000), pp. 85-112.

[19] A. Amouric, F. Verhé, R. Auria and L. Casalot, Study of a hexane-degrading consortium in a biofilter and in liquid culture: biodiversity, kinetics and characterization of degrading strains, FEMS Microbiol. Ecol. 55 (2006), pp. 239-247.

[20] F.X. Prenafeta-Boldú, M. Guivernau, G. Gallastegui, M. Vinas, G.S. de Hoog and A. Elías, Fungal/bacterial interactions during the biodegradation of TEX hydrocarbons (toluene, ethylbenzene and p-xylene) in gas biofilters operated under xerophilic conditions, FEMS Microbiol. Ecol. 80 (2012), pp. 722-734. 
[21] N. Khammar, L. Malhautier, V. Degrange, R. Lensi, J.J. Godon and J.L. Fanlo, Link between spatial structure of microbial communities and degradation of a complex mixture of volatile organic compounds in peat biofilters, J. Appl. Microbiol. 98 (2005), pp. 476-490.

[22] U. Friedrich, H. Van Langenhove, K. Altendorf and A. Lipski, Microbial community and physicochemical analysis of an industrial waste gas biofilter and design of $16 \mathrm{~S}$ rRNAtargeting oligonucleotide probes, Environ. Microbiol. 5 (2003), pp. 183-201.

[23] Z. Cai, D. Kim, G. Sorial, R. Saikaly, M. Zein and D. Oerther, Performance and microbial diversity of a trickle-bed air biofilter under interchanging contaminants, Eng. Life Sci. 6 (2006), pp. 37-42.

[24] P. San-Valero, J. Penya-Roja, F. Sempere and C. Gabaldón, Biotrickling filtration of isopropanol under intermittent loading conditions, Bioprocess Biosyst. Eng. (2012), DOI: 10.1007/s00449-012-0833-y

[25] R.I. Amann, W. Ludwig and K.H. Schleifer, Phylogenetic identification and in-situ detection of individual microbial-cells without cultivation, Microbiol. Rev. 59 (1995), pp. 143-169.

[26] T. Barcon, J. Alonso-Gutierrez and F. Omil, Molecular and physiological approaches to understand the ecology of methanol degradation during the biofiltration of air streams, Chemosphere 87 (2012), pp. 1179-1185.

[27] U. Friedrich, M.M. Naismith, K. Altendorf and A. Lipski, Community analysis of biofilters using fluorescence in situ hybridization including a new probe for the Xanthomonas branch of the class Proteobacteria, Appl. Environ. Microbiol. 65 (1999), pp. 3547-3554.

[28] P. Juteau, R. Larocque, D. Rho and A. LeDuy, Analysis of the relative abundance of different types of bacteria capable of toluene degradation in a compost biofilter, Appl. Microbiol. Biotechnol. 52 (1999), pp. 863-868.

[29] M. Stoffels, R. Amann, W. Ludwig, D. Hekmat and K. Schleifer, Bacterial community dynamics during start-up of a trickle-bed bioreactor degrading aromatic compounds, Appl. Environ. Microbiol. 64 (1998), pp. 930-939.

[30] S. Roy, J. Gendron, M. Delhomenie, L. Bibeau, M. Heitz and R. Brzezinski, Pseudomonas putida as the dominant toluene-degrading bacterial species during air decontamination by biofiltration, Appl. Microbiol. Biotechnol. 61 (2003), pp. 366-373.

[31] A. Iwanade, J.H. Jang, M. Hirai and M. Shoda, Enhancement of styrene removal by Pseudomonas sp. SR-5 in mixed culture with a benzoic acid-degrading bacterium in biofilter, Environ. Technol. 26 (2005), pp. 941-950.

[32] D.W. Park, S.S. Kim, S. Haam, I.S. Ahn, E.B. Kim and W.S. Kim, Biodegradation of toluene by a lab-scale biofilter inoculated with Pseudomonas putida DK-1, Environ. Technol. 23 (2002), pp. 309-318. 
[33] A. Loy, F. Maixner, M. Wagner and M. Horn, probeBase - an online resource for rRNAtargeted oligonucleotide probes: new features 2007, Nucleic Acids Res. 35 (2007), pp. D800D804.

[34] I. Jubany, J. Lafuente, J. Carrera and J.A. Baeza, Automated thresholding method (ATM) for biomass fraction determination using FISH and confocal microscopy,

J. Chem. Technol. Biotechnol. 84 (2009), pp. 1140-1145.

[35] L. Cabrol, L. Malhautier, F. Poly, A. Lepeuple and J. Fanlo, Bacterial dynamics in steady-state biofilters: beyond functional stability, FEMS Microbiol. Ecol. 79 (2012), pp. 260-271.

[36] F.J. Álvarez-Hornos, C. Lafita, V. Martínez-Soria, J.M. Penya-Roja, M.C. Pérez and C. Gabaldón, Evaluation of a pilot-scale biotrickling filter as a VOC control technology for the plastic coating sector, Biochem. Eng. J. 58-59 (2011), pp. 154-161.

[37] G. Mosqueda, M. Ramos-Gonzalez and J. Ramos, Toluene metabolism by the solventtolerant Pseudomonas putida DOT-T1 strain, and its role in solvent impermeabilization, Gene 232 (1999), pp. 69-76.

[38] T. Krell, J. Lacal, M.E. Guazzaroni, A. Busch, H. Silva-Jimenez, S. Fillet, J.A. ReyesDarias, F. Munoz-Martinez, M. Rico-Jimenez, et al, Responses of Pseudomonas putida to toxic aromatic carbon sources, J. Biotechnol. 160 (2012), pp. 25-32. 
Table 1. Experimental plan for the removal of isopropanol under intermittent loading conditions. EBRT: empty bed residence times; IL: inlet load.

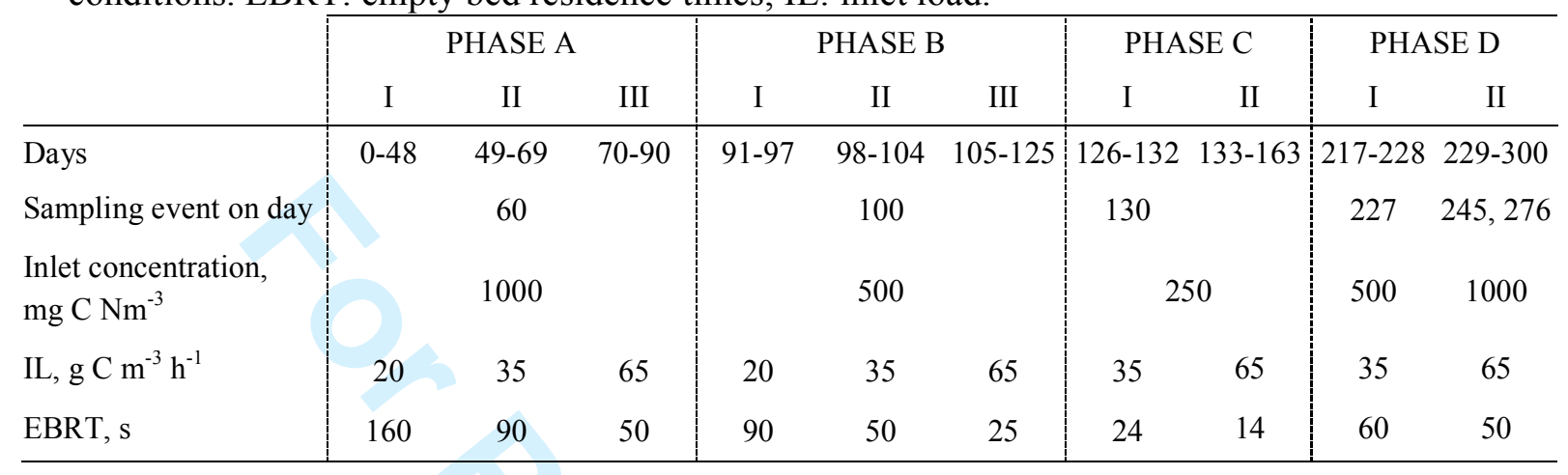


Table 2. List of oligonucleotide probes used in this study

\begin{tabular}{|c|c|c|c|}
\hline Probe & Specificity & Sequence, 5'-3' & Formamide, $\%$ \\
\hline$\overline{\text { EUB333 }^{\mathrm{a}}}$ & Most Bacteria & GCTGCCTCCCGTAGGAGT & $0-50$ \\
\hline EUB338-II ${ }^{\mathrm{a}}$ & Bacteria not detected by EUB338 & GCAGCCACCCGTAGGTGT & $0-50$ \\
\hline EUB338-III ${ }^{\mathrm{a}}$ & Bacteria not detected by EUB338 & GCTGCCACCCGTAGGTGT & $0-50$ \\
\hline ALF968 & $\alpha$-Proteobacteria & GGTAAGGTTCTGCGCGTT & 20 \\
\hline BET42A & $\beta$-Proteobacteria & GCCTTCCCACTTCGTTT & 35 \\
\hline - & Competitor for BET42A & GCCTTCCCACATCGTTT & 35 \\
\hline GAM42A & $\gamma$-Proteobacteria & GCCTTCCCACATCGTTT & 35 \\
\hline- & Competitor for GAM42A & GCCTTCCCACTTCGTTT & 35 \\
\hline HGC69A & $\begin{array}{l}\text { Actinobacteria } \\
\text { (high } G+C \text { Gram-positive } \\
\text { bacteria) }\end{array}$ & TATAGTTACCACCGCCGT & 25 \\
\hline - & Competitor for HGC69A & TATAGTTACGGCCGCCGT & 25 \\
\hline $\mathrm{LGC} 54 \mathrm{~A}^{\mathrm{b}}$ & $\begin{array}{l}\text { Firmicutes } \\
\text { (low G+C Gram-positive } \\
\text { bacteria) }\end{array}$ & TGGAAGATTCCCTACTGC & 35 \\
\hline $\mathrm{LGC} 34 \mathrm{~B}^{\mathrm{b}}$ & $\begin{array}{l}\text { Firmicutes } \\
\text { (low } G+C \text { Gram-positive } \\
\text { bacteria) }\end{array}$ & CGGAAGATTCCCTACTGC & 35 \\
\hline $\mathrm{LGC} 34 \mathrm{C}^{\mathrm{b}}$ & $\begin{array}{l}\text { Firmicutes } \\
\text { (low } G+C \text { Gram-positive } \\
\text { bacteria) }\end{array}$ & CCGAAGATTCCCTACTGC & 35 \\
\hline PS56a & Pseudomonas sp. & GCTGGCCTAGCCTTC & 0 \\
\hline Ppu56A & P. putida & GCTGGCCTAACCTTC & 0 \\
\hline REX72 & Bacillus & TGGGAGCAAGCTCCCAAAC & 20 \\
\hline Myc657 & Mycobacterium & AGTCTCCCCTGYAGTA & 30 \\
\hline
\end{tabular}

URL: http:/mc.manuscriptcentral.com/tent 
Table 3. Operational and performance parameters of both BTFs on the sampling days. EBRT: empty bed residence time; IL: inlet load; RE: removal efficiency.

\begin{tabular}{|c|c|c|c|c|c|c|c|c|}
\hline \multirow{2}{*}{$\begin{array}{l}\text { Sampling day } \\
\text { (Phase) }\end{array}$} & \multicolumn{2}{|c|}{ EBRT, s } & \multicolumn{2}{|c|}{$\begin{array}{l}\text { Inlet concentration, } \\
\mathrm{mg} \mathrm{C} \mathrm{Nm}^{-3}\end{array}$} & \multicolumn{2}{|c|}{$\begin{array}{l}\text { IL, } \\
\mathrm{g} \mathrm{C} \mathrm{m}^{-3} \mathrm{~h}^{-1}\end{array}$} & \multicolumn{2}{|l|}{$\mathrm{RE}, \%$} \\
\hline & BTF1 & BTF2 & BTF1 & BTF2 & BTF1 & BTF2 & BTF1 & BTF2 \\
\hline $60(\mathrm{~A}-\mathrm{II})$ & 90 & 90 & 1021 & 1035 & 41.0 & 38.0 & 85.6 & 86.6 \\
\hline 100 (B-II) & 52 & 51 & 530 & 517 & 34.0 & 33.4 & 89.6 & 90.9 \\
\hline $130(\mathrm{C}-\mathrm{I})$ & 27 & 27 & 298 & 295 & 37.0 & 38.8 & 81.4 & 88.7 \\
\hline \multicolumn{9}{|c|}{ Starvation period from day 164 to 217} \\
\hline 227 (D-I) & 59 & 60 & 632 & 630 & 35.3 & 34.5 & 89.7 & 94.6 \\
\hline 245 (D-II) & 48 & 49 & 898 & 1051 & 61.0 & 71.0 & 77.0 & 77.0 \\
\hline 276 (D-II) & 48 & 48 & 1091 & 1095 & 75.0 & 75.0 & 79.0 & 90.0 \\
\hline
\end{tabular}


Table 4. Total percentage values of the bacterial groups in both BTFs

\begin{tabular}{lll}
\hline $\begin{array}{l}\text { Sampling day } \\
\text { (Phase) }\end{array}$ & \multicolumn{2}{l}{ Total percentage value } \\
BTF1 & BTF2 \\
\hline 60 (A-II) & 29.7 & 69.4 \\
100 (B-II) & 62.2 & 76.5 \\
130 (C-I) & 64.9 & 60.1 \\
\hdashline Starvation period from day 164 to 217 \\
\hdashline 227 (D-I) & 72.9 & 76.1 \\
245 (D-II) & 63.9 & 61.9 \\
276 (D-II) & 79.2 & 88.1 \\
\hline
\end{tabular}


Figure 1. Schematic of the experimental set-up.

Figure2. Performance of the BTFs in removing isopropanol, (a) BTF1 and (b) BTF2. Arrows represent the days when biomass samples were taken. $(\bullet)$ Inlet Load, ( $\mathbf{X})$ Elimination Capacity and ( $\square)$ Removal Efficiency.

Figure 3. Time-dependent changes in bacterial community composition using general FISH probes. Results corresponding to (a) BTF1 and (b) BTF2.

Figure 4. Gammaproteobacteria in BTF2 on day 276. (a) General probe and (b) specific probe.

Figure 5. Time-dependent changes in bacterial community composition using specific FISH probes. Results corresponding to (a) BTF1 and (b) BTF2.

Figure 6. DGGE banding patterns of bacterial 16S rRNA from samples on days 60, 100, 227 and 276 in (a) BTF1 and (b) BTF2. Sample of a culture enriched with Pseudomonas putida was also included. 


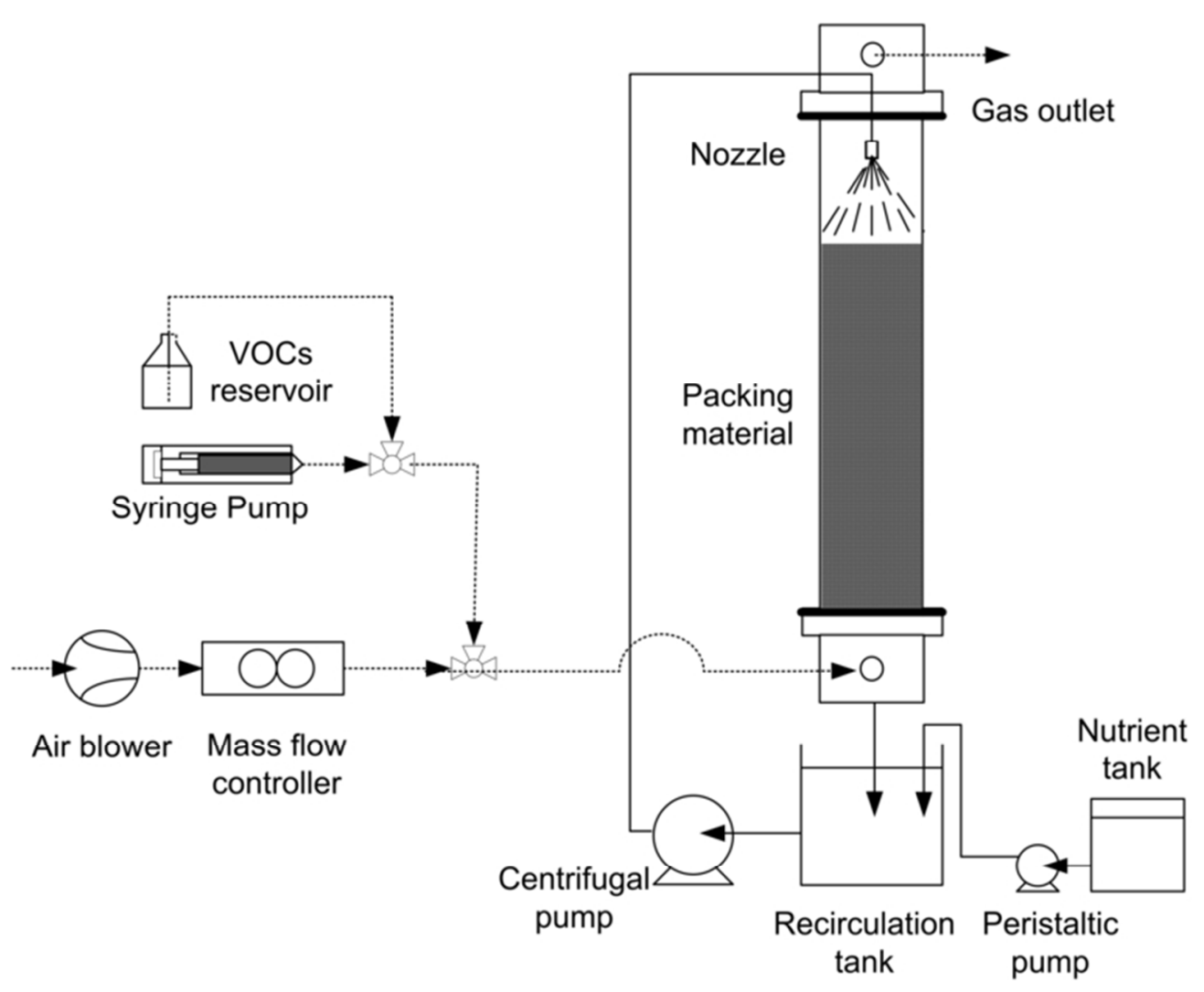

Figure 1. Schematic of the experimental set-up. $64 \times 52 \mathrm{~mm}(300 \times 300$ DPI $)$ 

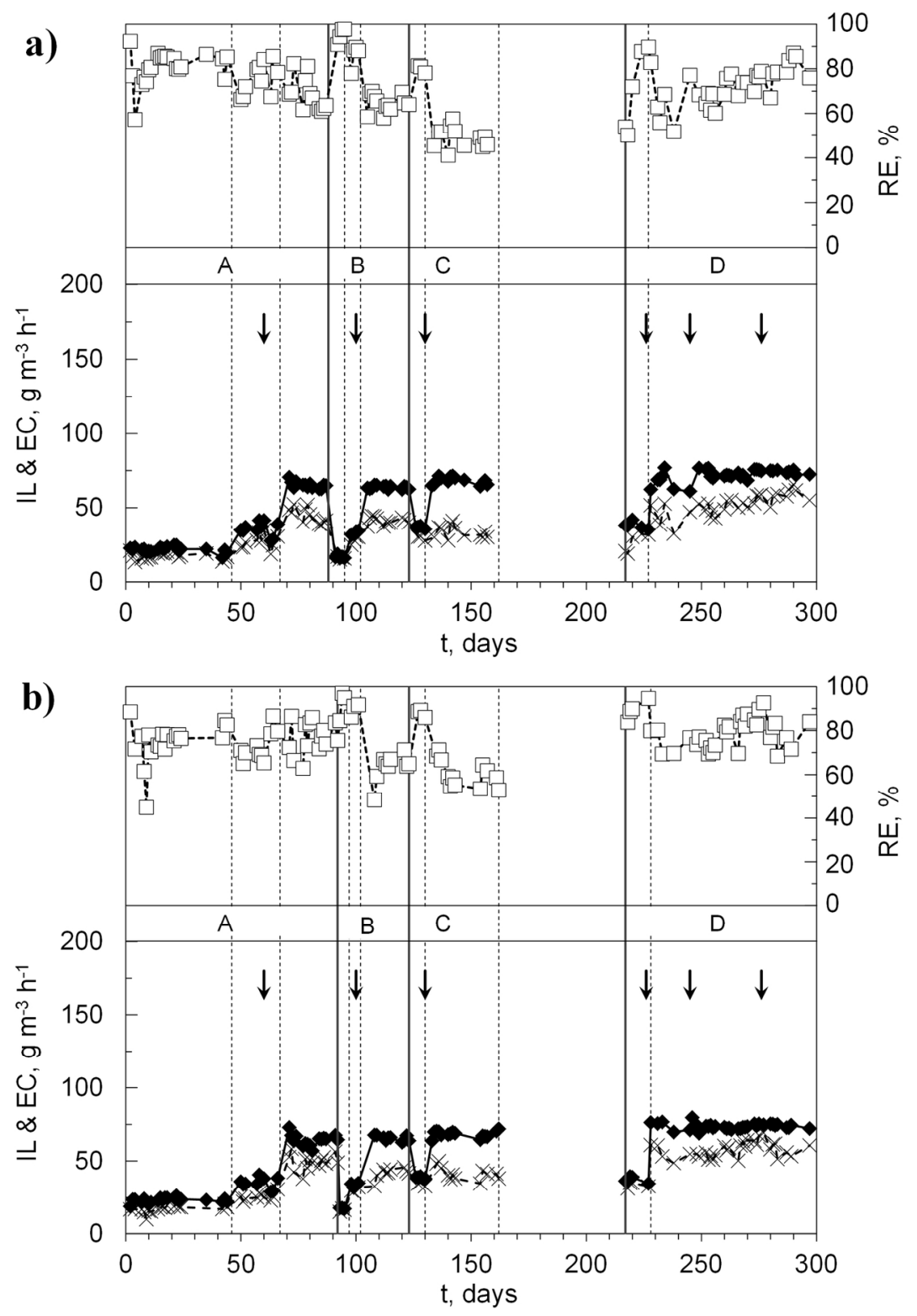

Figure 2. Performance of the BTFs in removing isopropanol, (a) BTF1 and (b) BTF2. Arrows represent the days when biomass samples were taken. (a) Inlet Load, (X) Elimination Capacity and (o) Removal Efficiency $131 \times 191 \mathrm{~mm}(300 \times 300 \mathrm{DPI})$ 

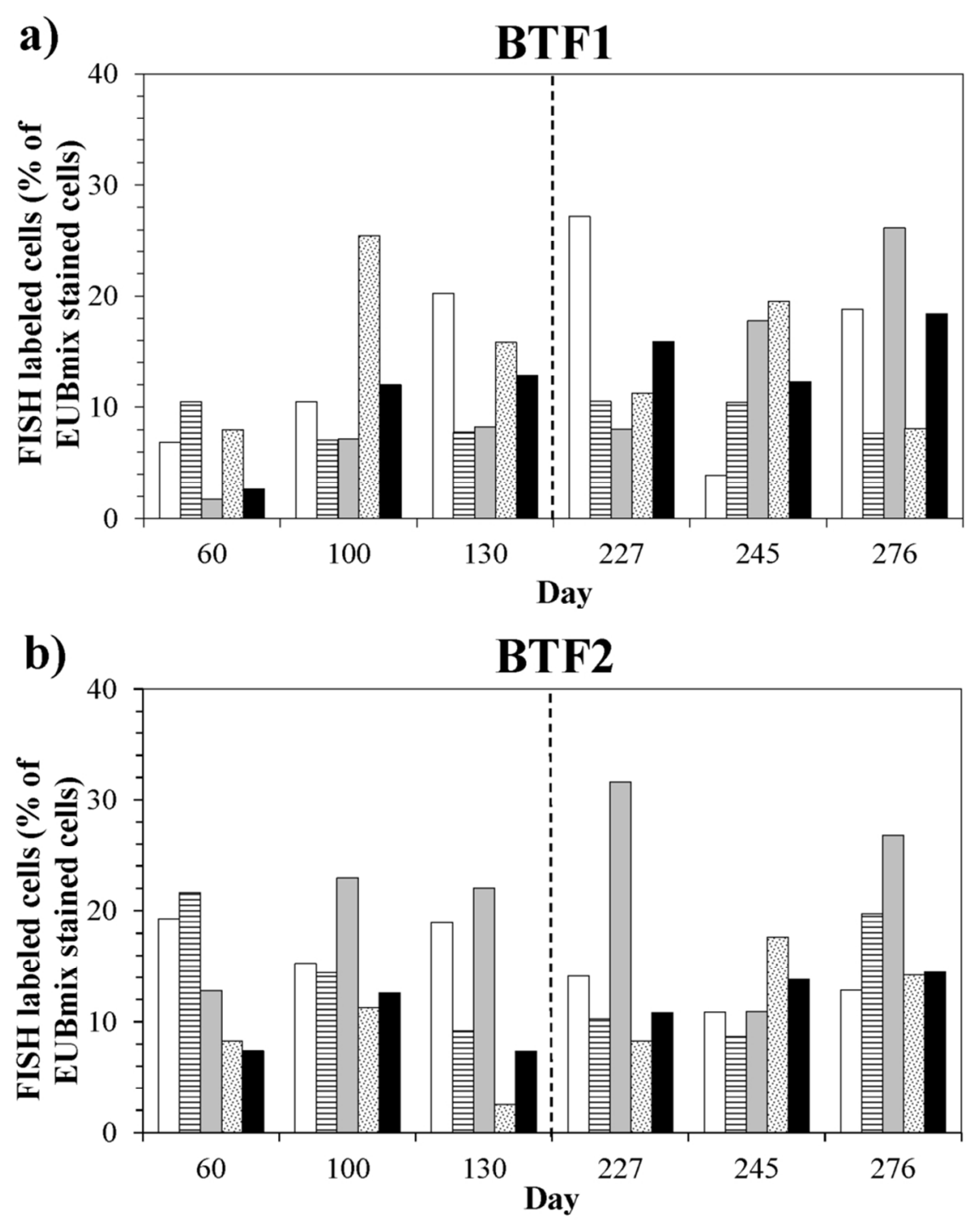

$\square$ Alphaproteobacteria 目Betaproteobacteria $\square$ Gammaproteobacteria 图 Firmicutes

- Actinobacteria

Figure 3. Time-dependent changes in bacterial community composition using general FISH probes. Results corresponding to (a) BFT1 and (b) BTF2. $99 \times 123 \mathrm{~mm}(300 \times 300 \mathrm{DPI})$ 


\section{a)}

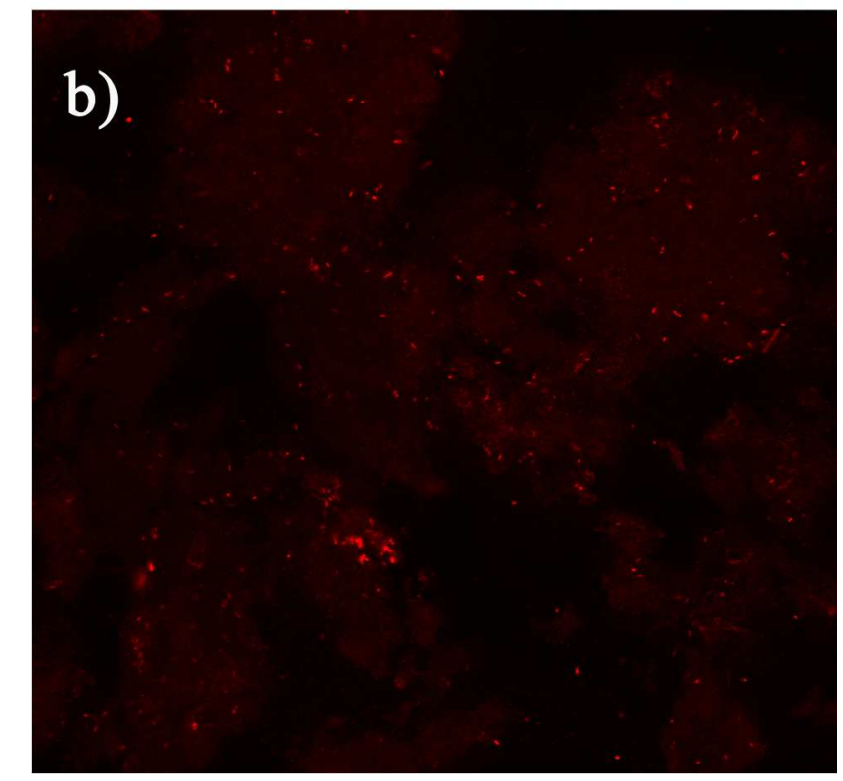

Figure 4. Gammaproteobacteria in BTF2 on day 276. (a) General probe and (b) specific probe. $154 \times 300 \mathrm{~mm}(300 \times 300$ DPI) 

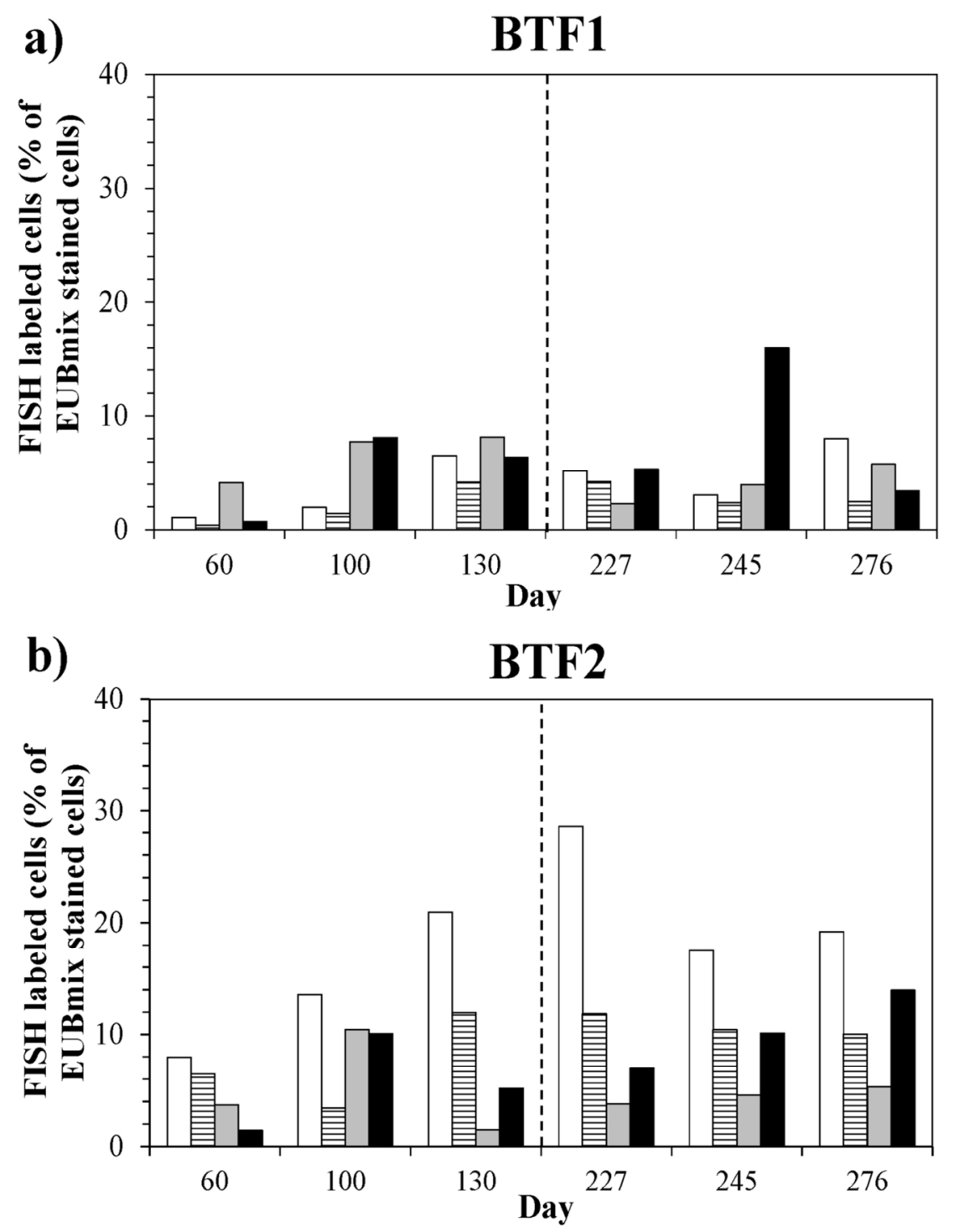

$\square$ Pseudomonas sp. 目P.putida $\square$ Bacillus $\quad$ Mycobacterium

Figure 5. Time-dependent changes in bacterial community composition using specific FISH probes. Results corresponding to (a) BFT1 and (b) BTF2. $107 \times 144 \mathrm{~mm}(300 \times 300 \mathrm{DPI})$ 

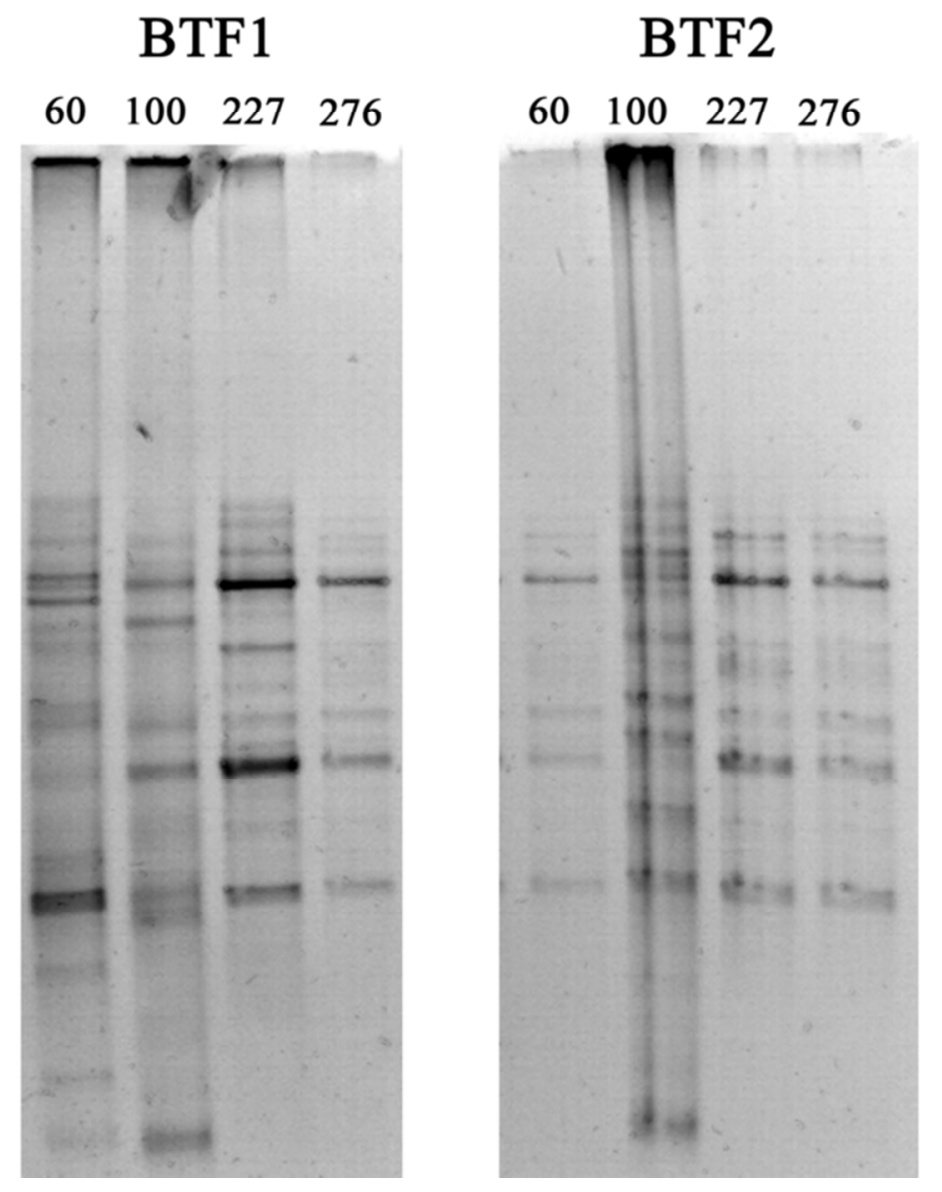

Pseudomonas

Putida

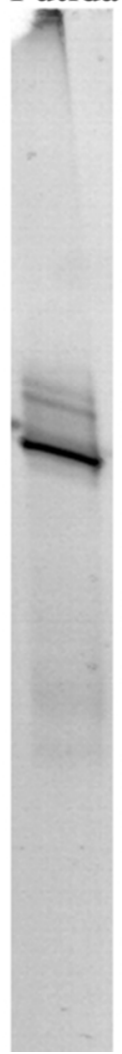

Figure 6. DGGE banding patterns of bacterial 16S rRNA from samples on days 60, 100, 227 and 276 in (a) BTF1 and (b) BTF2. Sample of a culture enriched with Pseudomonas putida was also included.

$73 \times 67 \mathrm{~mm}(300 \times 300$ DPI $)$ 